\title{
Effect of Liquid Break-Up Model Selection on Simulated Diesel Spray and Combustion Characteristics
}

\author{
Author, co-author (Do NOT enter this information. It will be pulled from participant tab in \\ MyTechZone) \\ Affiliation (Do NOT enter this information. It will be pulled from participant tab in MyTechZone)
}

\begin{abstract}
Accurate modelling for spray vapour fields is critical to enable adequate predictions of spray ignition and combustion characteristics of non-premixed reacting diesel sprays. Spray vapour characteristics are in turn controlled by liquid atomization and the KH-RT liquid jet break-up model is regularly used to predict this: with the $\mathrm{KH}$ model used for predicting primary break-up given its definition as a surface wave growth model, and the RT model used for predicting secondary break-up due to it being a drag based, stripping model. This paper investigates how the alteration of the switching position of the $\mathrm{KH}$ and RT sub-models within the KH-RT model impacts the resulting vapour field and ignition characteristics. The combustion prediction is handled by the implementation of a 54 species, 269 reaction skeletal mechanism utilising a Well Stirred Reactor model within the Star-CD CFD code. Following on from the derivation and implementation of an Ohnesorge based switch between the KH and RT sub-models, this model is now tested in igniting cases for an ndodecane fuelled single holed injection representing the ECN "Spray A" condition, and is compared to the baseline Reitz-Diwakar model. Differences in flame behaviour, particularly within the temperature distribution, are seen and directly traced from the effect of liquid break-up position and model selection, through atomised droplet size distribution and mixture fraction distribution. Different criteria for judging the ignition delays and lift-off-lengths are compared, with all methods predicting very similar results for both models. The KH and RT sub-models are also tested against each other, with heavy instabilities seen when the RT model is solely applied to the spray. This correlates with the instabilities shown in the vapour fields, suggesting the enabling of the RT model near-nozzle is to be avoided.
\end{abstract}

\section{Introduction}

Accurate modelling of diesel injection and combustion is paramount to improving efficiency of diesel engines through better engine simulations. Previous studies have been conducted to observe incylinder spray evolution, the air-fuel mixing process, auto-ignition and flame propagation [1-3]. However, these studies are commonly performed in rather simplified configurations which allow limited usage on engine design and optimization [4]. Computational Fluid Dynamics (CFD) allows for a level of vision within a cylinder that cannot be provided by standard optical-access engines, allowing researchers to see in-cylinder flows in unparalleled detail. Whereas a common engine is somewhat equivalent to a "black box", where the inputs and outputs from the engine are known but the exact knowledge of what is happening within the cylinder is not, CFD Page 1 of 16 allows for this to be visualised. Along with the increased knowledge of in-cylinder flows that CFD provides to researchers, it is also useful in engine development due to the relatively low cost and small lead time in setting up a CFD simulation in comparison to operating an optical-access engine. Parametric studies of engine components are also much faster to run in a virtual environment, with any changes able to be automated and run simultaneously on clustered computer systems, in comparison to being run sequentially on a real engine. The changeover time for the study would also need to be taken into account; for example the nozzle-tip protrusion study by Leach et al. [5] required only a small change in the CFD simulation, in comparison to requiring a technician to alter the injector position each time a test is required.

The Lagrangian-Eulerian approach is commonly used for modelling diesel sprays. A variety of different CFD codes and models have been used to study the characteristics of the spray. The KIVA-3V code has been used as a tool for early engine simulations by Senecal et al. [6], accurately predicting the liquid length, ignition delay and flame liftoff-length for differing ambient and injection conditions.

OpenFOAM is another commonly used CFD package, with Lucchini et al. [7] investigating a vaporising diesel spray condition to determine grid size requirements. The liquid length, vapour length and mixture fraction distributions were well predicted within this study. The comparatively newer CFD package CONVERGE has been very commonly used for diesel engine and spray simulations. Leach et al. [8] compared CONVERGE to an experimental diesel engine, with the simulation results mirroring the experimental trends seen at a variety of part and full-load operating points. Fang et al. [9] have also used CONVERGE to study the phenomenon of combustion recession on the ECN "Spray A" condition, with good matches for the experimental liquid length, vapour length, ignition delay and liftoff-lengths seen with different combustion models and skeletal mechanisms used. Bolla et al. [10] used the CFD software Star-CD to predict the turbulence-chemistry interaction for an n-heptane spray at engine conditions, comparing different combustion models with the same chemical mechanism. It was shown that a more complex Conditional Moment Closure (CMC) combustion model predicted the experimental lift-off-lengths better at most cases than a simpler Well Stirred Reactor (WSR) model, with negligible change on the ignition delay. The soot volume fraction predictions also differed between the models; however both were over-predicted when compared to experimental results. A split injection study using n-dodecane fuel was also undertaken in Star-CD by Blomberg et al. [11], using different turbulence models within their investigation. The combustion recession phenomenon was captured well by both 
models, as well as the vapour length, ignition delay and lift-offlengths.

In the following work the standard ECN "Spray A" condition will be simulated using a RANS framework in the Star-CD CFD code. Initially, the vaporising case will be considered, with the impact of a novel switching method for the KH-RT break-up model on the vapour fields established. This novel switching method will then be compared to another commonly used break-up model, the ReitzDiwakar model, at the combusting "Spray A" test point. Both cases will use the same methodology for solving the combustion chemistry, ensuring as controlled a comparison as possible between the two break-up models. The ignition delays, lift-off-lengths and temperature fields will be compared between the models, with differences investigated. The mixture fractions will also be compared and differences detailed, helping to explain the discrepancies seen before. Finally, the influence of each of the KH and RT models will be determined, with large oscillations seen in the RT model's case, mirroring results seen in the vapour field study.

\section{Computational Set-Up}

Within this paper the Star-CD CFD v4.30 code is used [12], modelling the diesel spray in a coupled Lagrangian-Eulerian method, with the spray droplets modelled as parcels as per the discrete droplet method proposed by Dukowicz [13] and the gas field modelled by the standard k- $\varepsilon$ turbulence model [14]. A grid dependency study was undertaken in the style of Senecal et al. [2], with convergence found in major computational parameters at a cell size of $0.25 \mathrm{~mm}$. Further information on this can be found in the authors' previous work [15]. The "effective" injection method is used, whereby the droplets are injected into the domain at nozzle diameter, with an injection velocity based on the injection mass flow rate, after which the droplets undergo break-up. The droplet drag is modelled by a dynamic drag relationship (Eq. A16). Other models for the turbulent dispersion [16] and vaporisation are used $[17,18]$, however these are described well in the literature and as a result are not fully presented here.

The Sandia constant volume chamber is modelled within Star-CD as a $108 \mathrm{~mm}$ cubic chamber [4] utilizing a structured, pre-generated mesh. The cell sizes vary from $2 \mathrm{~mm}$ as a base mesh to $0.25 \mathrm{~mm}$ in the near-nozzle region. The refinement is shown in Figure 1, clearly showing the steps in refinement employed to best capture the "Spray A" condition previously [15].

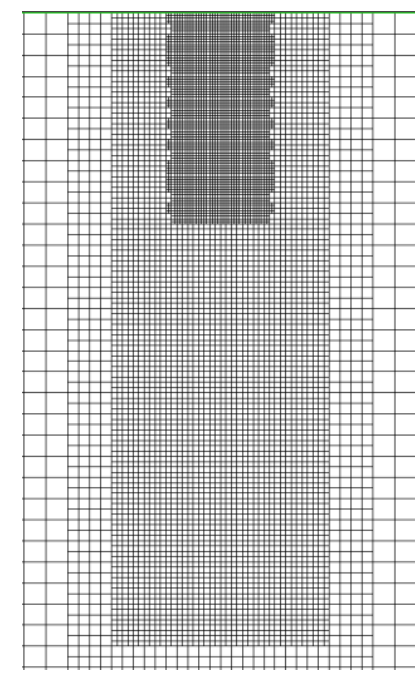

Figure 1 - Computational mesh employed in Star-CD for spray predictions, with refinement noted

\section{Break-Up Modelling}

Within this paper the Reitz-Diwakar [19] and the KH-RT break-up model [20,21] are used to predict droplet break-up. The ReitzDiwakar model is used in conjunction with the Huh-Gosman atomization model, in which the injection cone angle is calculated. When the KH-RT model was used, the injection cone angle was set to $20^{\circ}$. For the KH-RT model the addition of the Ohnesorge based break-up length as derived by the author previously is used [15]. From here on in this will be referred to as the KH-RT "Switch" model. The model acts to ensure that both $\mathrm{KH}$ and RT models act within the spray as previously it was found that the RT model would dominate the break-up, causing unphysical effects. A summary of the governing equations used within the KH and RT sub-models can be found in Appendix A, along with the model constants used within this paper. The main addition to the KH-RT model is the Ohnesorge based criterion, shown in Eq. 1.

$$
S W_{1}=10 S_{N} D_{0} Z_{0}
$$

The criterion is based on the nozzle diameter $\left(D_{0}\right)$, the initial Ohnesorge number $\left(Z_{0}\right)$ and a scaling number $\left(S_{N}\right)$ that controls the position of the switch between the KH and RT models. Before the criterion is met, the $\mathrm{KH}$ model acts; after this the $\mathrm{KH}$ and RT models compete based on the predicted break-up time as is used within Star-CD.

The constant values used within these simulations for the turbulence model are shown in Table 1, with the break-up model constants detailed in Appendix A. The main constant changed is the $S_{N}$ value, which will be noted where it is changed within the study. 
Table 1 - Turbulence model constants used within this study, altered to match the "Spray A" condition, with note of differences between break-up models

\begin{tabular}{|l|l|}
\hline Model Constant & Value \\
\hline $\mathrm{C}_{\mu}$ & 0.09 \\
\hline $\mathrm{C}_{1 \varepsilon}$ & $1.52(\mathrm{R}-\mathrm{D}) / 1.58(\mathrm{KH}-\mathrm{RT})$ \\
\hline $\mathrm{C}_{2 \varepsilon}$ & $1.92(\mathrm{R}-\mathrm{D}) / 1.96(\mathrm{KH}-\mathrm{RT})$ \\
\hline$\sigma_{\mathrm{k}}$ & 1 \\
\hline$\sigma_{\varepsilon}$ & 1.3 \\
\hline
\end{tabular}

\section{Combustion Modelling}

To model the combustion of n-dodecane within this paper the skeletal mechanism of Yao et al. [22] will be used, which is a 54 species, 269 reaction mechanism, allowing for the combustion of n-dodecane to be viewed a series of reversible reactions. The equation for the ideal (complete) combustion of n-dodecane is shown in Equation 2.

$$
\mathrm{C}_{12} \mathrm{H}_{26}+18.5 \mathrm{O}_{2} \rightarrow 12 \mathrm{CO}_{2}+13 \mathrm{H}_{2} \mathrm{O}
$$

Yao's mechanism was chosen due to its lower reaction count and hence quicker computational time than other available n-dodecane mechanisms like that of Wang et al. [23]. Given the combustion mechanism is used as a means of comparison and not as an in-depth combustion analysis a more complete mechanism is not required. However, this mechanism has been used in DNS [24], LES [25] and RANS [26,27] simulations with good results being seen in all studies. This mechanism has been shown to over-predict the lift-off-length when compared to the "Spray A" condition using RANS models [9], however given this mechanism is being used to solely compare the break-up models this is not a concern for this study.

Yao's mechanism was used in conjunction with a Well Stirred Reactor (WSR) model, under which each transport equation is solved at the same resolution as the cell size. This is implemented as standard within Star-CD, which applies a combination of a time-split method [12] and a Dynamic Multi-Zone (DMZ) method [28] to increase the computational efficiency of the combustion simulation. Within the DMZ method groups of cells are constructed using four characteristic quantities: temperature (representing combustion progress), mixture fraction (representing mixing progress), enthalpy (representing energy level), and mass fraction of auto-ignition species (such as $\mathrm{CH}_{2} \mathrm{O}$ and $\mathrm{H}_{2} \mathrm{O}_{2}$ ) to capture the auto-ignition process $[10,12,29]$. This method has been shown to predict the ignition of a diesel spray well, and has been compared to more complex combustion models such as Conditional Moment Closure (CMC), showing good matches to ignition delays and lift-off-lengths [10].

\section{Experimental Validation}

For this study the Engine Combustion Network (ECN) "Spray A" condition will be used. The "Spray A" test point is a high temperature and pressure case with well-characterised experimental data available for validation [30,31], with the conditions for this test point shown in Table 2. Within the Sandia set-up the conditions are reached using a Page 3 of 16 pre-burn chamber, whereby a small amount of fuel is ignited before the test, and the injection of note is started when the ambient conditions reach the desired temperature and pressure. As a result, the ambient gas composition contains combustion products in small quantities in addition to the $\mathrm{N}_{2}$ quantity. Further information on the exact Sandia set-up can be found in Pickett's initial paper on the ECN project [30]. The experimental data used for comparison is taken from the reacting study of Lillo et al. [32], with the $15 \% \mathrm{O}_{2}$ case used. The main comparison criteria are the ignition delay and lift-offlengths, with the experimental results shown in Table 3 . The lift-offlength is shown as a mean and $95 \%$ confidence interval, taken from the data provided by the ECN.

Table 2 - Reacting "Spray A” conditions [32]

\begin{tabular}{|l|l|}
\hline Fuel Surrogate & $\mathrm{n}$-dodecane \\
\hline Ambient Temperature (K) & 900 \\
\hline Ambient Gas Density $\left(\mathbf{k g} / \mathbf{m}^{\mathbf{3}}\right)$ & 22.8 \\
\hline Ambient Gas Composition & $\begin{array}{l}75.15 \% \mathrm{~N}_{2}, 15 \% \mathrm{O}_{2}, 6.22 \% \mathrm{CO}_{2}, \\
3.62 \% \mathrm{H}_{2} \mathrm{O}\end{array}$ \\
\hline Injection Pressure (bar) & 1500 \\
\hline Fuel Injection Temperature (K) & 363 \\
\hline Nozzle Diameter $(\boldsymbol{\mu m})$ & 90 \\
\hline Injection Duration $(\mathbf{m s})$ & 1.5 \\
\hline Injected Mass $(\mathbf{m g})$ & $3.5-3.7$ \\
\hline
\end{tabular}

Table 3 - Mean experimental lift-off-length and ignition delay for the reacting "Spray A" case [32]

\begin{tabular}{|c|c|}
\hline Lift-Off-Length $(\mathbf{m m})$ & Ignition Delay $(\mathbf{m s})$ \\
\hline $16.60 \pm 3.98$ & 0.43 \\
\hline
\end{tabular}

For the computational definitions of lift-off-length and ignition delay, common definitions will be used. Within this paper three different definitions for lift-off-length will be tested, based on the axial distance to either an $\mathrm{OH}$ mass fraction or a temperature threshold. The $\mathrm{OH}$ thresholds are commonly used and are defined as either $2 \%$ or $14 \%$ of the Favre-averaged simulation maximum, with the temperature threshold defined as $400 \mathrm{~K}$ above the ambient temperature. These criteria have been used to calculate lift-off-length previously [23,33,34], with good results for all criteria shown. The ignition delay is similarly defined based on the $\mathrm{OH}$ mass fraction, however in this case it is the first timestep at which the $\mathrm{OH}$ mass fraction exceeds the set thresholds. The vapour fields are also based on a commonly used criterion, with the field defined as the volume in which cells contain higher than $0.1 \%$ mass fraction of fuel vapour.

\section{Non-Reacting Vapour Field Predictions}

Within the initial derivation of the KH-RT "Switch" model the impact of the switching position on the vapour fields was not considered [15]. Given the importance of good prediction of the vapour fields on the combustion of the spray, it is critical to consider how implementing a break-up length model impacts this prediction. Three separate switching positions will be considered at the nonreacting case, with $S_{N}$ values of 68.0, 203.9 and 543.8 used (corresponding to switching positions of 1,3 and $8 \mathrm{~mm}$ from the injector tip respectively). Along with this, the baseline Reitz-Diwakar 
(R-D) case will also be considered. These cases were considered in the previous study [15], with the liquid length means and vapour lengths shown in Table 4. As can be seen, the switching position has minimal impact on the vapour length at either 1 or $1.5 \mathrm{~ms}$ ASOI, and all the switching positions chosen closely match the baseline ReitzDiwakar case's vapour length.

Table 4 - Mean liquid length and vapour lengths for the $S_{N}=68.0$, 203.9 and 543.8 cases along with the baseline Reitz-Dwiakar case for the vaporising "Spray A" condition

\begin{tabular}{|l|c|c|c|}
\hline Break-Up Model & $\begin{array}{c}\text { Liquid Length } \\
\text { Mean }\end{array}$ & $\begin{array}{c}\text { Vapour } \\
\text { Length @ 1 } \\
\text { ms ASOI }\end{array}$ & $\begin{array}{c}\text { Vapour } \\
\text { Length @ 1.5 } \\
\text { ms ASOI }\end{array}$ \\
\hline $\mathrm{S}_{\mathrm{N}}=68.0$ & $10.11 \mathrm{~mm}$ & $43.5 \mathrm{~mm}$ & $52.5 \mathrm{~mm}$ \\
\hline $\mathrm{S}_{\mathrm{N}}=203.9$ & $10.01 \mathrm{~mm}$ & $42.5 \mathrm{~mm}$ & $52.5 \mathrm{~mm}$ \\
\hline $\mathrm{S}_{\mathrm{N}}=543.8$ & $9.55 \mathrm{~mm}$ & $43.5 \mathrm{~mm}$ & $53.0 \mathrm{~mm}$ \\
\hline Reitz-Diwakar & $10.13 \mathrm{~mm}$ & $43.5 \mathrm{~mm}$ & $53.5 \mathrm{~mm}$ \\
\hline Experimental & $10.08 \pm 0.34 \mathrm{~mm}$ & $46.8 \mathrm{~mm}$ & $56.9 \mathrm{~mm}$ \\
\hline
\end{tabular}

The cone angles predicted by each position offer an insight into the capturing of the spray, and the predictions for each position are shown in Table 5, with the experimental data (from Sandia [30]) also shown. All cone angles are calculated using the method of Naber and Siebers [35], where the angle is taken to half the vapour penetration length at each time considered.

Table 5 - Computational and experimental cone angles, in degrees, calculated from the vapour fields at varying times ASOI

\begin{tabular}{|l|c|c|c|c|c|}
\hline $\mathbf{S}_{\mathbf{N}}$ & $\mathbf{0 . 5} \mathbf{~ m s}$ & $\mathbf{0 . 7 5} \mathbf{~ m s}$ & $\mathbf{1 ~ m s}$ & $\mathbf{1 . 2 5} \mathbf{~ m s}$ & Mean \\
\hline 68.0 & 18.2 & 19.4 & 19.2 & 19.3 & 19.0 \\
\hline 203.9 & 19.1 & 19.0 & 19.4 & 19.8 & 19.4 \\
\hline 543.8 & 18.7 & 19.3 & 19.6 & 20.0 & 19.4 \\
\hline R-D & 23.4 & 22.3 & 22.5 & 22.5 & 22.7 \\
\hline Experimental & 23.4 & 22.1 & 24.3 & 23.2 & 23.3 \\
\hline
\end{tabular}

The cone angle defined for the simulations was $20^{\circ}$, given it was used for comparison with another CFD code as in the previous study [15]. It is worth noting that the Reitz-Diwakar case uses the Huh-Gosman atomization model, which calculates the cone angle as part of the simulation and as such differs in prediction in comparison to the $\mathrm{KH}-$ RT "Switch" model. Comparing the vapour field boundaries between the $S_{N}=68.0$ case and the experimental data in Figure 2 shows the difference in cone angle predictions, with the difference accounted by a lack of prediction of eddies within the simulations results, especially apparent on the "bottom" side of the spray in Figure 2. Given the use of a RANS modelling system for these simulations this is not surprising, especially when considering a comparison between a RANS simulation and a single experimental spray. As such, it is not deemed an issue, especially given the generally good prediction of the "top" side of the spray shown in Figure 2.

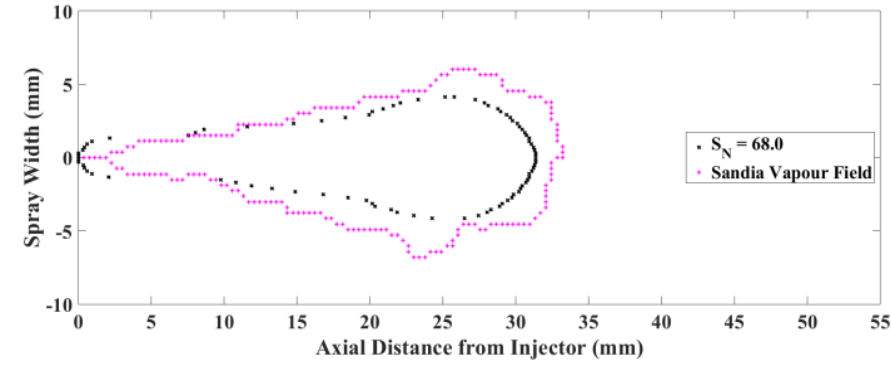

Figure 2 - Plot at $0.5 \mathrm{~ms}$ ASOI of the spray vapour boundary fields of the $S_{N}=68.0$ case and the instantaneous experimental spray data

Comparing the different switching positions using the KH-RT "Switch" model, a clear oscillation in the near nozzle vapour field can be seen in the $S_{N}=68.0$ case in Figure 3. This was believed to be due to numerical convergence issues caused by the near nozzle switching position and is not seen in either of the other cases. This oscillation can also be seen in later snapshots of the spray, as shown in Figure 4 at 1.25 ms ASOI. These results suggest a boundary needs to be placed on the value of $S_{N}$ to ensure that convergence issues do not arise.

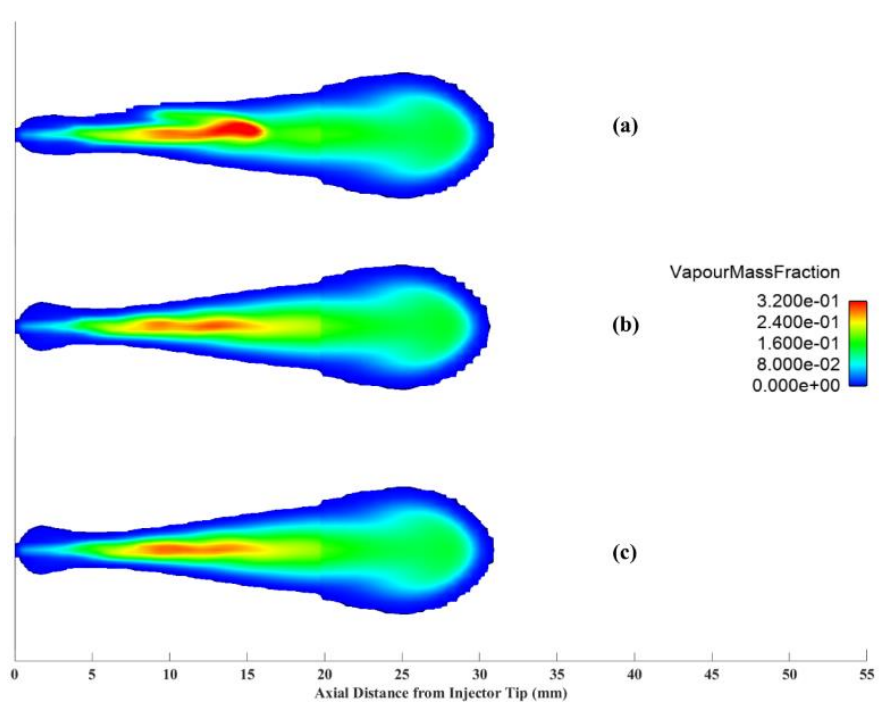

Figure 3 - Vapour mass fractions for the non-reacting "Spray A" case at $0.5 \mathrm{~ms}$ ASOI, with $\mathrm{S}_{N}$ values of (a) 68.0, (b) 203.9 and (c) 543.8 


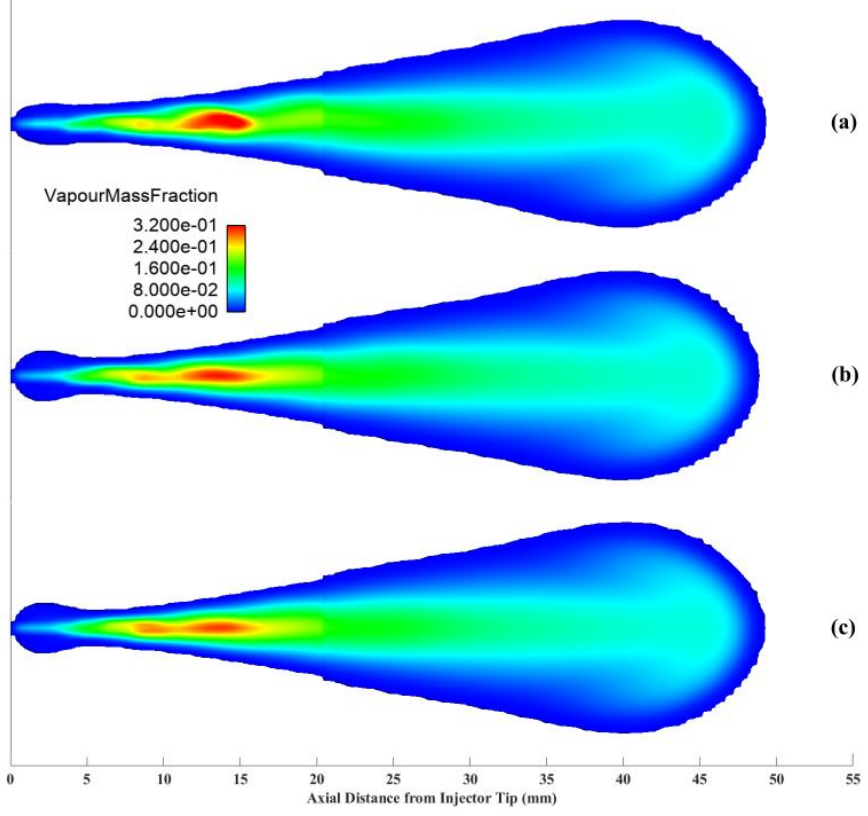

Figure 4 - Vapour mass fractions for the non-reacting "Spray A" case at $1.25 \mathrm{~ms}$ ASOI, with $S_{N}$ values of (a) 68.0, (b) 203.9 and (c) 543.8

For the $\mathrm{S}_{\mathrm{N}}$ values of 203.9 and 543.8, the vapour fields predicted are very similar to each other, with no oscillatory behaviour shown and vapour length predictions closely aligned. Given the switching position's impact on liquid length shown in the previous study [15], a value of 203.9 will be used for the combusting results in the next section. This value is of further importance given the better prediction of steady state liquid length it provides over the 543.8 value [15].

\section{Combusting Results}

\section{Break-Up Model Comparison}

Within this section the KH-RT "Switch" model will be compared against the baseline Reitz-Diwakar model at the combusting "Spray A" test point. To ensure that the cases are compared properly the vapour and liquid lengths are matched through tuning of the constants shown in Tables 1, A1 and A2. This ensures the two cases are matched to each other as closely as possible at the non-reacting "Spray A" case, as is shown in Table 6. The model setups for the two cases are then used for the combusting "Spray A" case. The liquid length means are calculated between $0.3 \mathrm{~ms}$ and $1.5 \mathrm{~ms}$, as before [15].

Table 6 - Liquid length means and vapour lengths for the KH-RT "Switch" and Reitz-Diwakar models for the non-reacting "Spray A" case

\begin{tabular}{|l|c|c|c|}
\hline Break-Up Model & $\begin{array}{c}\text { Liquid Length } \\
\text { Mean }\end{array}$ & $\begin{array}{c}\text { Vapour } \\
\text { Length @ 1 } \\
\text { ms ASOI }\end{array}$ & $\begin{array}{c}\text { Vapour } \\
\text { Length @ 1.5 } \\
\text { ms ASOI }\end{array}$ \\
\hline KH-RT “Switch" & $10.01 \mathrm{~mm}$ & $42.5 \mathrm{~mm}$ & $52.5 \mathrm{~mm}$ \\
\hline Reitz-Diwakar & $10.13 \mathrm{~mm}$ & $43.5 \mathrm{~mm}$ & $53.5 \mathrm{~mm}$ \\
\hline Experimental & $10.08 \pm 0.34 \mathrm{~mm}$ & $46.8 \mathrm{~mm}$ & $56.9 \mathrm{~mm}$ \\
\hline
\end{tabular}

The vapour length matches between the two models are very close, ensuring that the comparisons made are valid. To begin with, the ignition delays for both break-up models are compared. The results for these are shown in Table 7, showing a very good match to the experimental ignition delay for both models. The difference in the $\mathrm{OH}$ criterion has a minimal impact on the prediction of the ignition delay, which is further shown when the progression of the $\mathrm{OH}$ mass fraction is plotted against time, as in Figure 5.

Table 7 - Simulated and experimental ignition delays for the combusting "Spray A" case

\begin{tabular}{|l|c|}
\hline \multicolumn{1}{|c|}{ Break-Up Model } & Ignition Delay (ms) \\
\hline KH-RT “Switch" $-2 \% \mathrm{OH}_{\max }$ & 0.43 \\
\hline KH-RT "Switch" - $14 \% \mathrm{OH}_{\max }$ & 0.44 \\
\hline Reitz-Diwakar $-2 \% \mathrm{OH}_{\max }$ & 0.42 \\
\hline Reitz-Diwakar - $14 \% \mathrm{OH}_{\max }$ & 0.44 \\
\hline Experimental & 0.43 \\
\hline
\end{tabular}

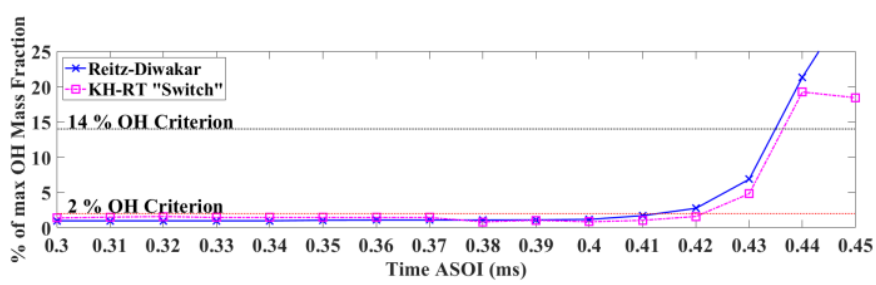

Figure 5 - Simulated \% $\mathrm{OH}_{\max }$ against time for both break-up models at the combusting "Spray A" case

Within the DMZ model various auto-ignition scalars are used to help simulate the ignition of the spray, chief among which are the $\mathrm{CH}_{2} \mathrm{O}$ and $\mathrm{H}_{2} \mathrm{O}_{2}$ species. Comparing these between the break-up models at their $2 \% \mathrm{OH}_{\max }$ ignition delay helps to ascertain the combustion model is consistent when using either break-up model, and is shown in Figure 6 and 7. Along with this, the mixture fractions and temperatures of the two break-up models are also compared. The larger cone angle for the Reitz-Diwakar model is clearly shown within the temperature fields, however otherwise the fields are very similar to each other with magnitudes of each scalar considered closely matched between the two models.

Reitz-Diwakar@0.42 ms ASOI

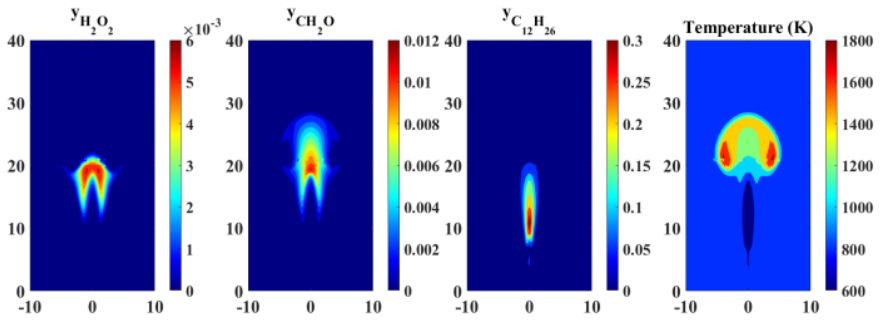

Figure $6-\mathrm{H}_{2} \mathrm{O}_{2} . \mathrm{CH}_{2} \mathrm{O}, \mathrm{C}_{12} \mathrm{H}_{26}$ and temperature fields at the predicted $2 \% \mathrm{OH}_{\max }$ ignition delay for the Reitz-Diwakar model. Distances are in $\mathrm{mm}$

Page 5 of 16 
KH-RT "Switch"@ 0.43 ms ASOI

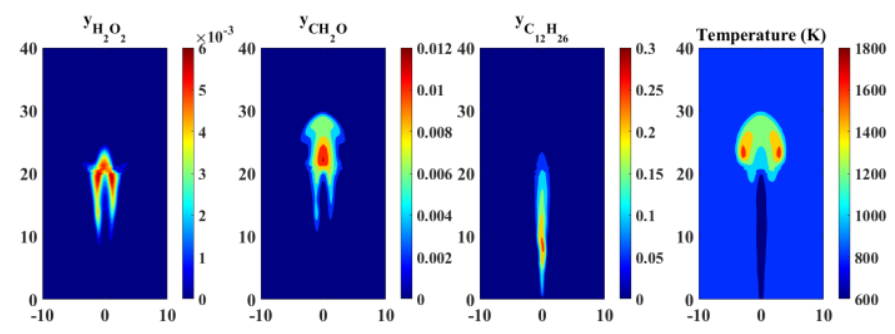

Figure $7-\mathrm{H}_{2} \mathrm{O}_{2}, \mathrm{CH}_{2} \mathrm{O}, \mathrm{C}_{12} \mathrm{H}_{26}$ and temperature fields at the predicted $2 \% \mathrm{OH}_{\max }$ ignition delay for the $\mathrm{KH}-\mathrm{RT}$ "Switch" model. Distances are in $\mathrm{mm}$

Considering the lift-off-lengths, the additional criterion of $\mathrm{T}_{\mathrm{amb}}+400 \mathrm{~K}$ is considered. Figure 8 shows the comparison of the lift-off-lengths after the start of combustion between the simulations and experimental data. As can be seen, initially the lift-off-lengths are predicted well, however as combustion continues the lift-off-lengths diverge from the experimental results before returning within the experimental variation at the end of the simulated time. Comparing between the break-up models, the Reitz-Diwakar model predicts a slightly lower lift-off-length initially, however the models converge around the end of injection to predict very similar lift-off-lengths. Finally, the $\mathrm{OH}$ and temperature criteria appear to make very little difference to the predicted lift-off-lengths, with only a minor divergence seen in the Reitz-Diwakar model at $1.25 \mathrm{~ms}$ to $1.75 \mathrm{~ms}$, however generally all criteria predict very similar lift-off-lengths. This over-prediction of lift-off-lengths is seen when using both a well stirred reactor model $[10,36,37]$ and the Yao mechanism $[9,38]$. Along with this, as the study seeks to compare the break-up models against one another utilising the same combustion model, the trends seen between the models are similar and as such can be considered a function of both the combustion model and mechanism used.

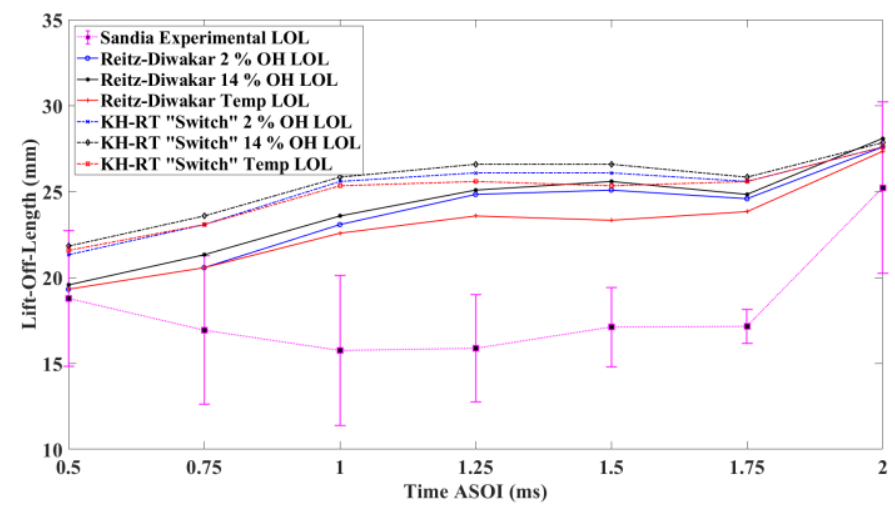

Figure 8 - Simulated and experimental lift-off-lengths for the combusting "Spray A" condition against time ASOI. Experimental data shown as a mean and $95 \%$ confidence interval through error bars

Considering the progression of the combustion, snapshots are taken from each break-up model's simulation at 1 and $1.5 \mathrm{~ms}$ ASOI. Figure 9 shows the difference in predictions of $\mathrm{OH}$ and temperature between the two break-up models. As can be seen, the Reitz-Diwakar case has a noticeably wider spray plume at both times shown, with the shorter lift-off-length shown in Figure 8 visible at $1 \mathrm{~ms}$ ASOI. The KH-RT "Switch" model also penetrates further with both the $\mathrm{OH}$ and

Page 6 of 16 temperature fields at $1 \mathrm{~ms}$ ASOI, however this difference in penetration is reduced as the injection continues. Another interesting observation is that the $2 \% \mathrm{OH}_{\max }$ boundary matches very well with the high temperature regions of the spray confirming the initial reasoning behind selecting this criterion as a predictor of combustion zones. This comparison is shown in Figure 10, showing the $2 \%$ $\mathrm{OH}_{\max }$ boundary closely following the red temperature boundary of $2000 \mathrm{~K}$ within the spray plume, especially in the KH-RT "Switch" model predictions. 

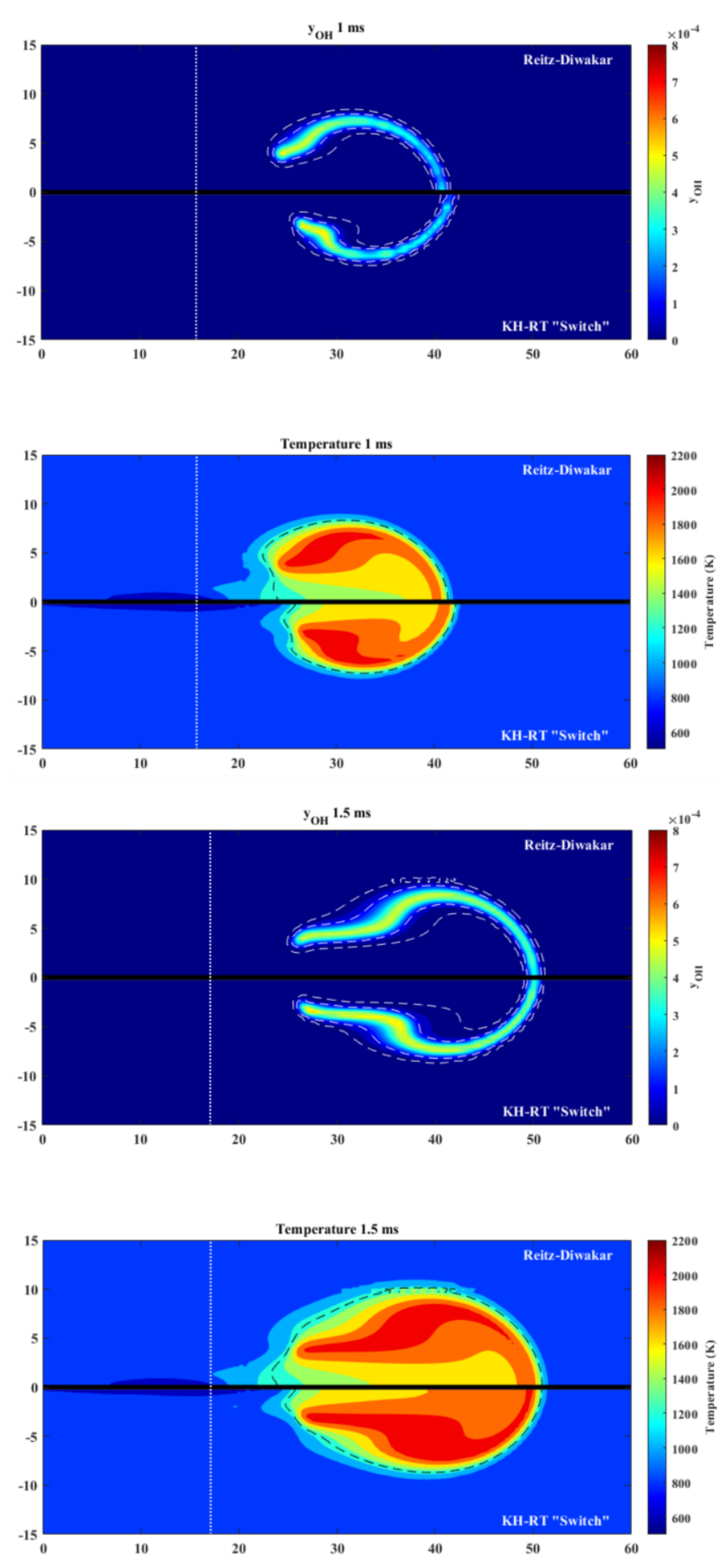

Figure 9 - $O H$ and temperature field plots for the Reitz-Diwakar and KH-RT "Switch" models at $1 \mathrm{~ms}$ and $1.5 \mathrm{~ms}$ ASOI. The $2 \%$ and $14 \%$ $\mathrm{OH}_{\max }$ criteria are shown as dashed white lines with the temperature criterion shown as a dashed black line. The experimental lift-offlengths are shown as a white dotted line
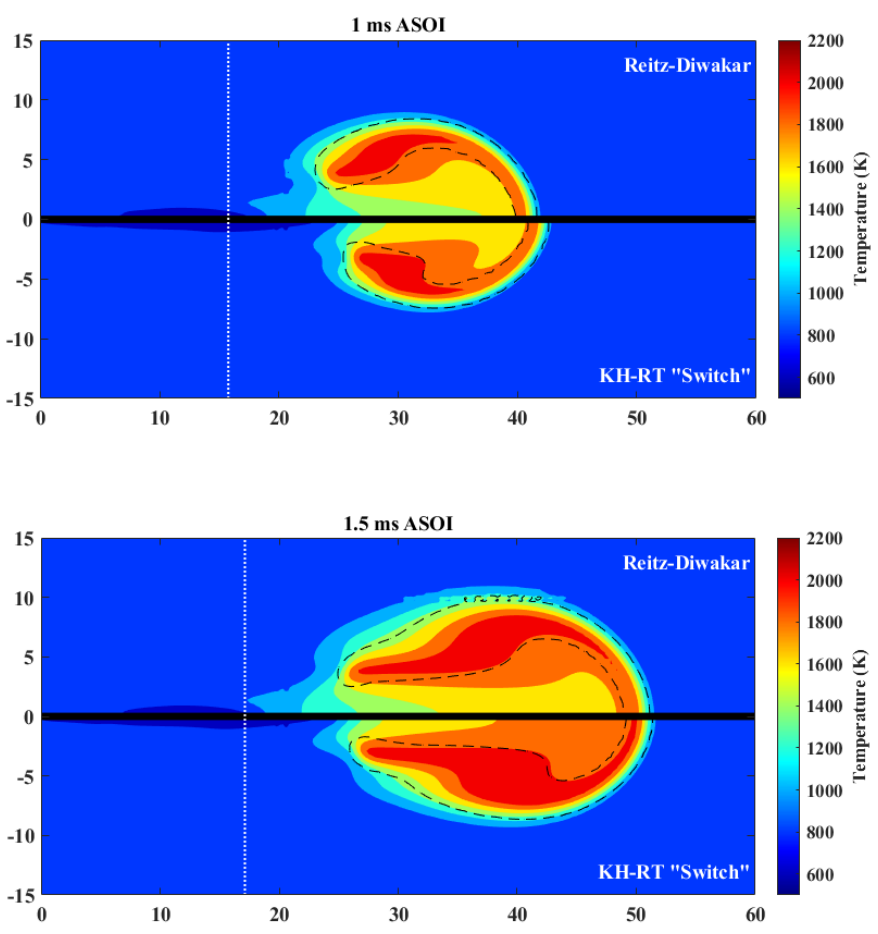

Figure 10 - Temperature fields for the Reitz-Diwakar and KH-RT "Switch" models at $1 \mathrm{~ms}$ and $1.5 \mathrm{~ms}$ ASOI, with the $2 \% \mathrm{OH}_{\max }$ boundary shown as a black dashed line. The experimental lift-offlengths are shown as a white dotted line

Figure 10 also shows a difference in the temperature in the centre of the spray between the two models, with the KH-RT "Switch" model predicting a hotter "core" of the spray than the Reitz-Diwakar model. This suggests greater internal mixing of the fuel within the core of the spray, allowing for combustion to occur in more areas for the KH-RT "Switch" model. Along with this, the area encompassed by temperatures above ambient is lower in the KH-RT "Switch" model, suggesting a faster and locally hotter reaction than in the ReitzDiwakar model. This is reflected by the maximum centreline plane temperatures, as shown in Figure 11. The KH-RT "Switch" model shows a clearly higher temperature by approximately $45 \mathrm{~K}$ than the Reitz-Diwakar model for the majority of the simulation time.

However, considering the mean centreline plane temperatures, as shown in Figure 12, it can be seen that the Reitz-Diwakar model has a higher mean centreline plane temperature than the KH-RT "Switch" model at all timesteps. This is most likely due to the larger cone angles seen in the Reitz-Diwakar model (as seen in Table 5) ensuring that the combusting zone is larger for this model in comparison to the KH-RT "Switch" model. The larger combustion zone will ensure that more of the spray centreline plane is above the ambient temperature and hence this will lead to a larger mean temperature on that plane when compared to the KH-RT "Switch" model, by approximately $15 \mathrm{~K}$ at $0.5 \mathrm{~ms}$ ASOI to $35 \mathrm{~K}$ at $2 \mathrm{~ms}$ ASOI. 


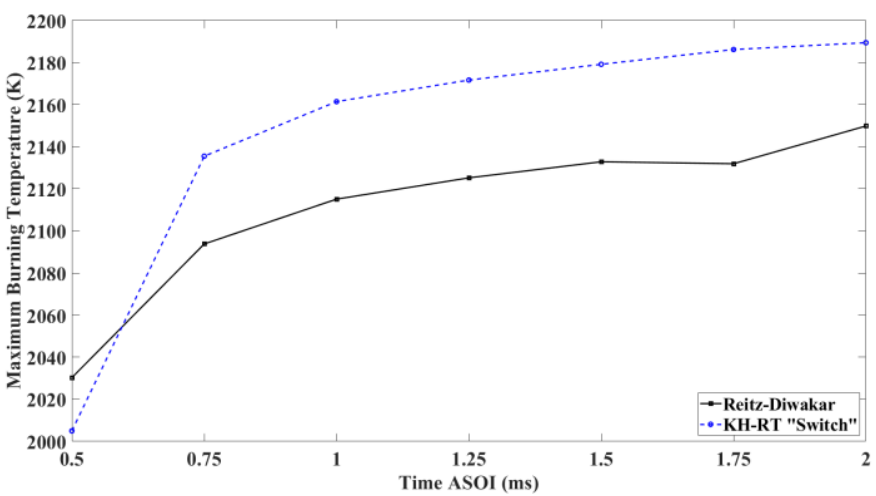

Figure 11 - Maximum centreline plane temperatures for the ReitzDiwakar and KH-RT "Switch" models for the combusting "Spray A" case against time ASOI

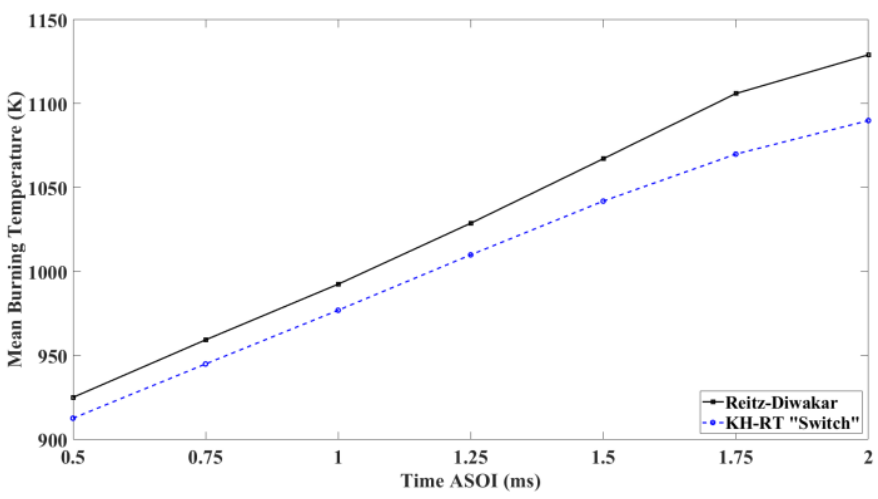

Figure 12 - Mean centreline plane temperatures for the ReitzDiwakar and KH-RT "Switch" models for the combusting "Spray A" case against time ASOI

Some of the difference between the maximum and mean centreline plane temperature predictions can be explained through consideration of the mixture fractions, as shown in Figure 13. The higher peak for the KH-RT "Switch" model at $20 \mathrm{~mm}$ from the injector tip is believed to be responsible for the higher maximum temperatures seen with this model. In comparison, the wider mixture fraction profile of the Reitz-Diwakar model at both positions correlates well with both the cone angle predictions and the more uniform temperature predictions seen for this model. These predictions also match the SMD predictions shown in the previous study [15], suggesting the vaporising case trends correlate well with the combusting case results.
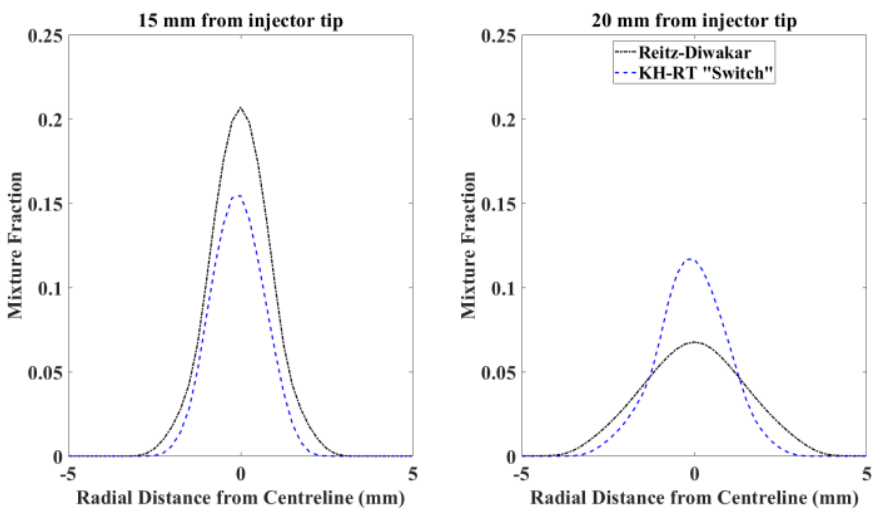

Figure 13 - Mixture fractions for the Reitz-Diwakar and KH-RT "Switch" models for the combusting "Spray A" case at $1 \mathrm{~ms}$ ASOI, at distances 15 and $20 \mathrm{~mm}$ from the injector tip

\section{KH and RT Sub-Model Influence}

Within this section the $\mathrm{KH}$ and RT sub-models will be tested independently of each other, utilising the switching position to force the break-up model to only apply one of the sub-models. Given the close predictions of lift-off-length seen between the criteria previously, the $2 \% \mathrm{OH}_{\max }$ criterion will be used within this section. The lift-off-lengths for the KH and RT sub-models are shown in Figure 14, showing a clear difference in the lift-off-length prediction between the two sub-models. The RT sub-model predicts a much lower lift-off-length than the KH sub-model throughout the injection period, and broadly matches the experimental data. Meanwhile, the KH sub-model matches the original KH-RT "Switch" model's liftoff-length (from Figure 8) closely throughout the injection period, showing good agreement with the other simulated combusting cases. The RT OH field is highly asymmetrical however, with the lift-offlength being determined by the lower half of the $\mathrm{OH}$ field which protrudes further from the spray tip and closer to the injector. This behaviour is shown in Figure 15. In comparison, the $\mathrm{KH} \mathrm{OH}$ field is highly symmetrical, with the lift-off-lengths between the two halves of the $\mathrm{OH}$ field being very close. The reason for this difference between the sub-models is believed to be instabilities in the liquid region of the RT sub-model's injection, with much more extreme oscillatory behaviour seen than was shown previously.

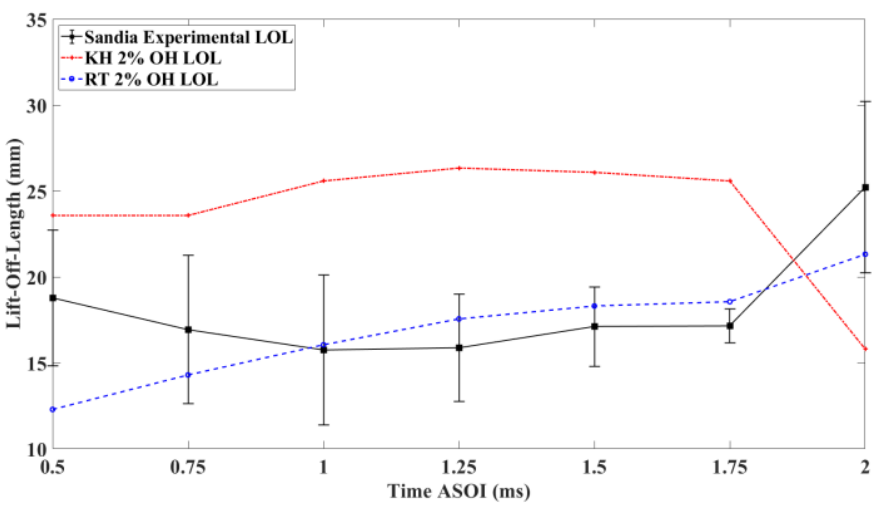

Figure 14 - Lift-off-lengths for the KH and RT sub-models, compared with the combusting "Spray A" lift-off-length, plotted against time ASOI. Experimental data shown as a mean and $95 \%$ confidence interval through error bars

Page 8 of 16 

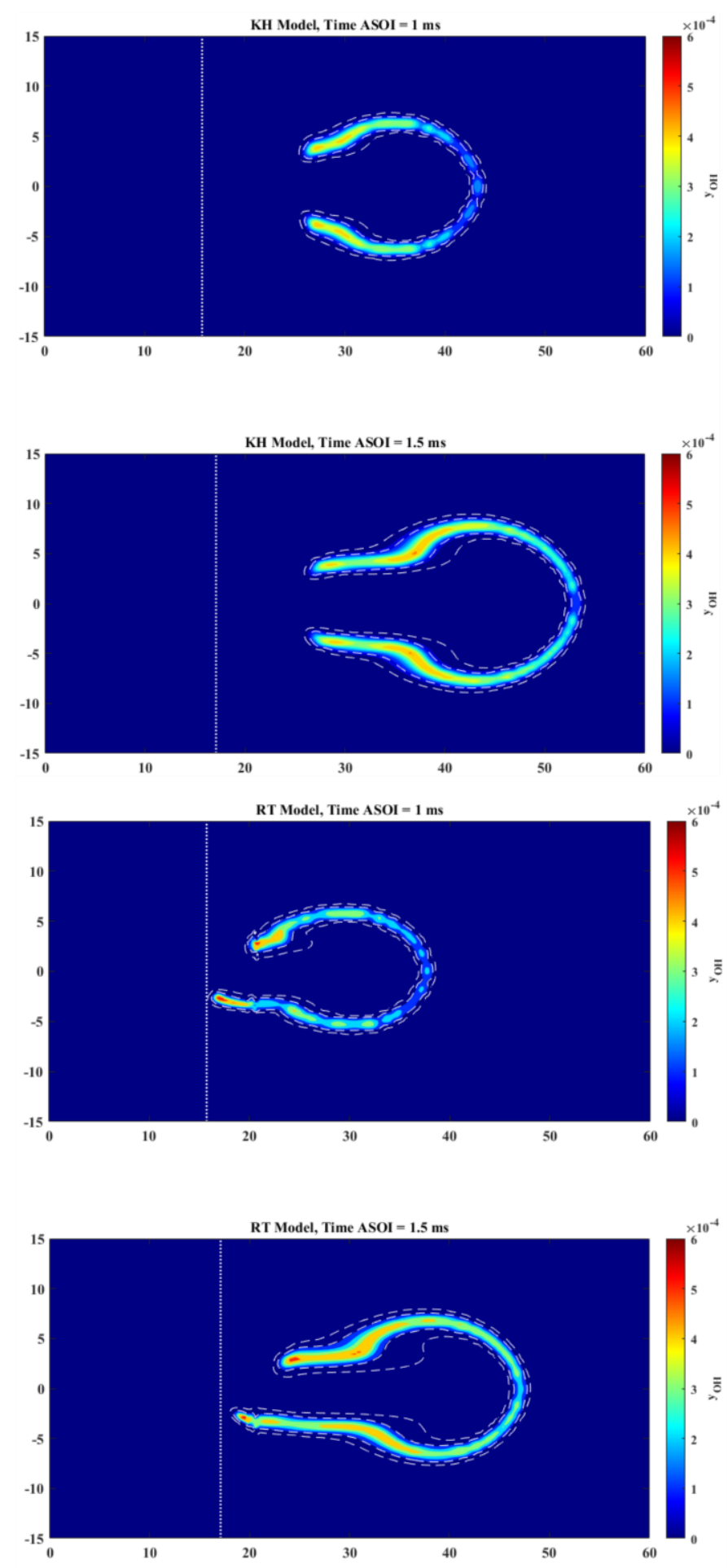

Figure 15 - OH field plots for the KH and RT sub-models at $1 \mathrm{~ms}$ and $1.5 \mathrm{~ms}$ ASOI. The 2 and $14 \% \mathrm{OH}_{\max }$ fields are shown as white dashed lines, and the experimental lift-off-length is shown by a dotted white line

These instabilities are shown in Figure 16, clearly showing large oscillations near the spray tip early on in the injection phase. Given the large amount of parcels below the spray centreline in comparison to above it the differences in the $\mathrm{OH}$ fields shown in Figure 15 can be explained by these parcels combusting closer to the spray tip than the ones above the spray centreline. Similar instabilities were seen when $\mathrm{S}_{\mathrm{N}}$ was set to very low values previously, with numerical errors generating the oscillatory behaviour. This holds true when the RT sub-model is the only one to act on the spray, however having an aerodynamic based break-up regime acting on the entirety of the spray is not realistic to a real-life situation. The instabilities seen within the RT model case also have a large impact on the mixture fraction predictions, as is shown in Figure 17. This figure shows the increasingly off-centre position of the maximum mixture fraction as the distance to the nozzle tip is increased from $15 \mathrm{~mm}$ to $20 \mathrm{~mm}$ at $1 \mathrm{~ms}$ ASOI, along with the corresponding reduction in mixture fraction as expected. This change in position of the maximum mixture fraction matches both the parcel plots shown in Figure 16 and $\mathrm{OH}$ fields shown in Figure 15, with the RT model predicting an extremely offset lift-off-length skewed towards the right hand side of the injector.

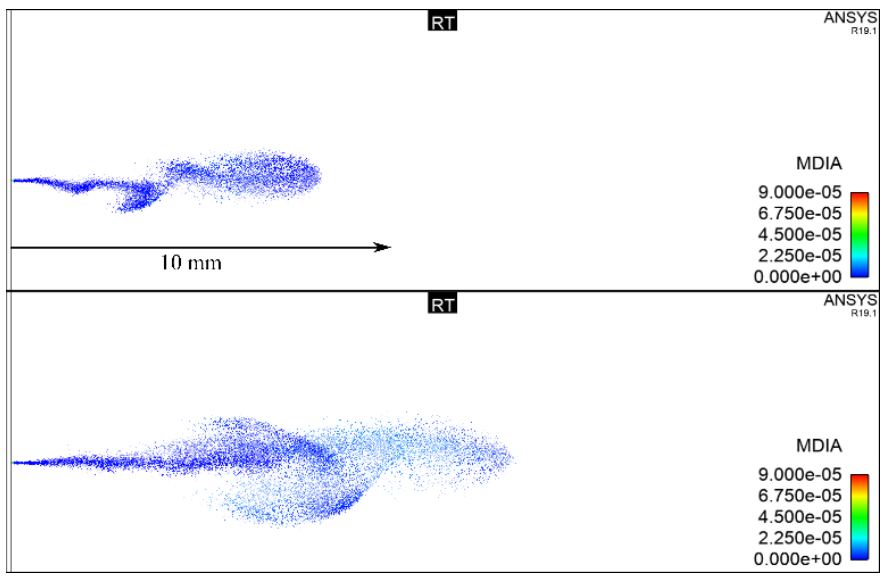

Figure 16 - Parcel plots for the RT sub-model simulation of the combusting "Spray A" case, at $0.1 \mathrm{~ms}$ ASOI (top) and $0.2 \mathrm{~ms}$ ASOI (bottom). MDIA is the droplet diameter in metres

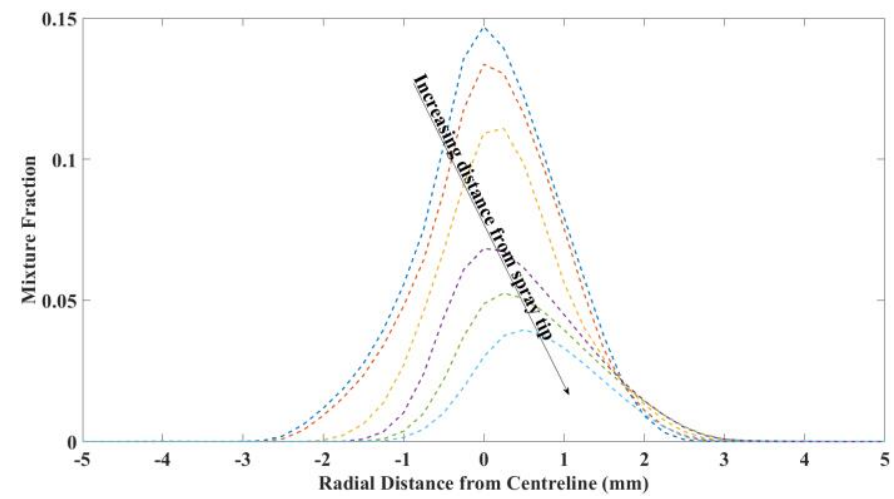

Figure 17 - Mixture fractions for the RT sub-model at distances of 15 to $20 \mathrm{~mm}$, in increments of $1 \mathrm{~mm}$, all taken at $1 \mathrm{~ms}$ ASOI

\section{Summary/Conclusions}

This paper has taken the KH-RT "Switch" model derived in the previous study and applied it to a combusting "Spray A" condition, with a good match found between the KH-RT "Switch" model and the baseline Reitz-Diwakar case when both models utilised the same reduced $n$-dodecane mechanism. The following differences and phenomena were also found and discussed: 
- $\quad$ The impact of the break-up model on the spray vapour fields has been characterised, with switching positions closer to the nozzle showing oscillatory behaviour throughout the injection time. This was seen to have no impact on the cone angle of the spray.

- Both models were found to over-predict the lift-off-length of the spray when compared to experimental results, with the Reitz-Diwakar model showing an over-prediction of the lift-off-length by approximately $7 \mathrm{~mm}$ and the KH-RT "Switch" model over-predicting the lift-off-length by approximately $10 \mathrm{~mm}$. This was deemed to not be an issue given this result has been seen previously when the combination of the well mixed combustion model and Yao mechanism was used. The ignition delay was predicted excellently on the other hand, with both break-up models matching experimental data to within $0.01 \mathrm{~ms}$.

- Differences in the mixture fractions were seen between the two models, with the results complementing the SMD results from the KH-RT "Switch" model derivation; these differences are also believed to cause the small differences seen in the temperature predictions.

- The influence of each sub-model of the KH-RT break-up model was also considered, utilising the implemented switch to ensure that only one model acted for the spray. The results showed that the RT sub-model caused a highly unstable liquid prediction, leading to a much lower lift-offlength than that of the $\mathrm{KH}$ sub-model. These instabilities mirrored those seen previously when the switch position was set too close to the injector, further suggesting a boundary on the switching constant is required.

\section{References}

1. Siebers DL, Higgins B. Flame Lift-Off on Direct-Injection Diesel Sprays Under Quiescent Conditions. SAE Tech Pap [Internet]. 2001; Available from: http://papers.sae.org/2001-01-0530/

2. Senecal PK, Pomraning E, Richards KJ, Som S. Grid-Convergent Spray Models for Internal Combustion Engine Computational Fluid Dynamics Simulations. J Energy Resour Technol [Internet]. 2013;136:012204. Available from:

http://energyresources.asmedigitalcollection.asme.org/article.aspx?do $\mathrm{i}=10.1115 / 1.4024861$

3. Koss H, Wiartalla A, Backer H. Spray Propagation, Mixture Formation, Auto-Ignition and Soot Formation of Multi-Component Fuels in a Pressure Chamber. IDEA-EFFECT 2nd Period Rep. 1993;515-42.

4. Pickett LM, Genzale CL, Bruneaux G, Malbec L, Hermant L, Christiansen C, et al. Comparison of Diesel Spray Combustion in Different High-Temperature, High-Pressure Facilities. SAE Tech Pap. 2010;2010-01-21:156-81.

5. Leach F, Ismail R, Davy M. Engine-out emissions from a modern high speed diesel engine - The importance of Nozzle Tip Protrusion. Appl Energy [Internet]. Elsevier; 2018;226:340-52. Available from: https://doi.org/10.1016/j.apenergy.2018.05.117

6. Senecal PK, Pomraning E, Richards KJ, Briggs TE, Choi CY, McDavid RM, et al. Multi-dimensional modeling of direct-injection diesel spray liquid length and flame lift-off length using cfd and parallel detailed chemistry. SAE Tech Pap. 2003;

Page 10 of 16
7. Lucchini AT, Errico GD, Ettorre D, Ferrari G, Sae S, Journal I, et al. Numerical Investigation of Non-Reacting and Reacting Diesel Sprays in Constant-Volume Vessels Linked references are available on JSTOR for this article: You may need to $\log$ in to JSTOR to access the linked references . Numerical Investigation of Non-Reac. SAE Int J Fuels Lubr. 2009;2:966-75.

8. Leach F, Ismail R, Davy M, Weall A, Cooper B. The effect of a stepped lip piston design on performance and emissions from a highspeed diesel engine. Appl Energy [Internet]. Elsevier; 2018;215:67989. Available from: https://doi.org/10.1016/j.apenergy.2018.02.076

9. Fang X, Ismail R, Davy MH, Camm J. Numerical Studies of Combustion Recession on ECN Diesel Spray A. ASME 2018 Intern Combust Engine Div Fall Tech Conf. San Diego; 2018. p. 1-13.

10. Bolla M, Farrace D, Wright YM, Boulouchos K, Mastorakos E. Influence of turbulence-chemistry interaction for $\mathrm{n}$-heptane spray combustion under diesel engine conditions with emphasis on soot formation and oxidation. Combust Theory Model [Internet]. Taylor \& Francis; 2014;18:330-60. Available from: http://dx.doi.org/10.1080/13647830.2014.898795

11. Blomberg CK, Zeugin L, Pandurangi SS, Bolla M, Boulouchos K, Wright YM. Modeling Split Injections of ECN "Spray A" Using a Conditional Moment Closure Combustion Model with RANS and LES. SAE Int J Engines. 2016;9:2107-19.

12. CD-adapco. Star-CD®version 4.30 Methodology. 2017.

13. Dukowicz JK. A particle-fluid numerical model for liquid sprays. J Comput Phys. 1980;35:229-53.

14. Launder BE, Spalding DB. The Numerical Computation Of Turbulent Flows. Numer Predict Flow, Heat Transf Turbul Combust [Internet]. Elsevier; 1983 [cited 2018 Jan 30]. p. 96-116. Available from:

http://linkinghub.elsevier.com/retrieve/pii/B9780080309378500167

15. Nicholson L, Fang X, Camm J, Davy M, Richardson D. Comparison of Transient Diesel Spray Break-Up between Two Computational Fluid Dynamics Codes. SAE Tech Pap. 2018;1-13.

16. Gosman AD, Ioannides E. Aspects of computer simulation of liquid-fuelled combustors. AIAA 19th Aerosp Sci Meet AIAA-810323, St Louis, USA. 1981.

17. El Wakil MM, Uyehara OA, Myers PS. A theoretical investigation of the heating-up period of injected fuel droplets vaporizing in air. 1954.

18. Ranz WE, Marshall WR. Evaporation from drops - Part 1. Chem. Eng. Prog. 1952. p. 141-8.

19. Reitz RD, Diwakar R. Effect of Drop Breakup on Fuel Sprays. SAE Tech Pap. 1986;860469.

20. Beale JC, Reitz RD. Modeling spray atomization with the KelvinHelmholtz/Rayleigh-Taylor hybrid model. At Sprays. 1999;9.

21. Xin J, Ricart L, Reitz RD. Computer modeling of diesel spray atomization and combustion. Combust Sci Technol. 1998;137:17194. 
22. Yao T, Pei Y, Zhong B, Som S, Lu T. A Hybrid Mechanism for n-Dodecane Combustion with Optimized Low-Temperature Chemistry. Fuel. 2017;191.

23. Wang H, Ra Y, Jia M, Reitz RD. Development of a reduced ndodecane-PAH mechanism and its application for n-dodecane soot predictions. Fuel [Internet]. Elsevier Ltd; 2014;136:25-36. Available from: http://dx.doi.org/10.1016/j.fuel.2014.07.028

24. Borghesi G, Krisman A, Lu T, Chen JH. Direct numerical simulation of a temporally evolving air / n-dodecane jet at lowtemperature diesel-relevant conditions. Combust Flame. Elsevier Inc.; 2018;195:183-202.

25. Ma PC, Wu H, Jaravel T, Bravo L, Ihme M. Large-eddy simulations of transcritical injection and auto-ignition using diffuseinterface method and finite-rate chemistry. Proc Combust Inst [Internet]. Elsevier Inc.; 2019;37:3303-10. Available from: https://doi.org/10.1016/j.proci.2018.05.063

26. Kim N, Jung K, Kim Y. Multi-environment PDF modeling for ndodecane spray combustion processes using tabulated chemistry. Combust Flame [Internet]. Elsevier Inc.; 2018;192:205-20. Available from: https://doi.org/10.1016/j.combustflame.2018.02.004

27. Chishty MA, Bolla M, Hawkes ER, Pei Y, Kook S. Soot formation modelling for $\mathrm{n}$-dodecane sprays using the transported PDF model. Combust Flame [Internet]. Elsevier Inc.; 2018;192:10119. Available from:

https://doi.org/10.1016/j.combustflame.2018.01.028

28. Liang L, Stevens JG, Farrell JT. A dynamic multi-zone partitioning scheme for solving detailed chemical kinetics in reactive flow computations. Combust Sci Technol. 2009;181:1345-71.

29. Westbrook CK. Chemical kinetics of hydrocarbon ignition in practical combustion systems. Proc Combust Inst. 2000;28:1563-77.

30. Pickett LM, Genzale CL, Bruneaux G, Malbec L, Hermant L, Christiansen C, et al. Comparison of Diesel Spray Combustion in Different High-Temperature, High-Pressure Facilities. SAE Int J Engines. 2010;3:156-81.

31. Pickett LM. ECN Website [Internet]. 2017 [cited 2018 Feb 3]. Available from: http://www.ecn.sandia.gov

32. Lillo PM, Pickett LM, Persson H, Andersson O, Kook S. Diesel Spray Ignition Detection and Spatial/Temporal Correction. SAE Int J Engines [Internet]. 2012;5:1330-46. Available from: http://papers.sae.org/2012-01-1239/

33. Desantes JM, Garcia-Oliver JM, Novella R, Perez-Sanchez EJ. Application of an unsteady flamelet model in a RANS framework for spray A simulation. Appl Therm Eng [Internet]. Elsevier Ltd; 2017;117:50-64. Available from: http://dx.doi.org/10.1016/j.applthermaleng.2017.01.101
34. Fang X, Ismail R, Davy M. A Study on Kinetic Mechanisms of Diesel Fuel Surrogate n-Dodecane for the Simulation of Combustion Recession. SAE Tech Pap. 2019;1-12.

35. Naber J, Siebers DL. Effects of Gas Density and Vaporization on Penetration and Dispersion of Diesel Sprays. SAE Tech Pap [Internet]. 1996; Available from: http://papers.sae.org/960034/

36. Bhattacharjee S, Haworth DC. Simulations of transient n-heptane and $n$-dodecane spray flames under engine-relevant conditions using a transported PDF method. Combust Flame [Internet]. The Combustion Institute.; 2013;160:2083-102. Available from: http://dx.doi.org/10.1016/j.combustflame.2013.05.003

37. Kim S, Jarrahbashi D, Genzale C. The Role of TurbulentChemistry Interaction in Simulating End-of-Injection Combustion Transients in Diesel Sprays. SAE Tech Pap. 2017;

38. Jarrahbashi D, Kim S, Knox BW, Genzale CL. Computational analysis of end-of-injection transients and combustion recession. Int $\mathbf{J}$ Engine Res. 2017;8.

39. Reitz RD. Modeling Atomization Processes in High-Pressure Vaporizing Sprays. At Sprays. 1987;3:309-37.

40. Joseph DD, Belanger J, Beavers GS. Breakup of a liquid drop suddenly exposed to a high-speed airstream. Int J Multiph Flow. 1999;25:1263-303.

\section{Contact Information}

The author can be contacted at slfnicholson@gmail.com.

\section{Acknowledgments}

The authors would like to thank the EPSRC and Jaguar Land Rover for their financial support, along with Rickard Solsjo at Siemens for his technical support. 


\section{Appendix A - Break-Up Model Comparison}

Within Star-CD, the droplet break-up rate is calculated as follows:

$$
\frac{d D_{d}}{d t}=-\frac{D_{d}-D_{d, \text { stable }}}{\tau}=-\frac{2\left(r_{p}-r_{c}\right)}{\tau}
$$

The initial droplet diameter, $\mathrm{D}_{\mathrm{d}}$, or the parent droplet radius $\mathrm{r}_{\mathrm{p}}$, are taken from the droplet properties and used to calculated the stable droplet

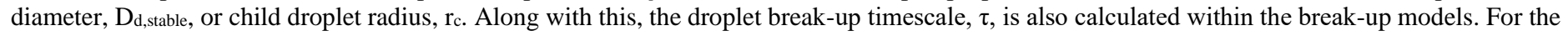
Reitz-Diwakar model the bag and strip models compete with each other, with the shortest predicted timescale determining which model acts. For the KH-RT model the KH model acts before the $\mathrm{SW}_{1}$ criterion is met (Eq. 1), after which both the KH and RT models compete with each other in the same way as the Reitz-Diwakar model.

\section{Reitz-Diwakar Break-Up Model}

The Reitz-Diwakar model simulates the break-up of the droplet in a bag-strip style, caused by the aerodynamic forces on the droplet [19]. The governing equations for the model are found below.

\section{Bag Break-Up}

For bag break-up to occur the droplet Weber number must exceed a critical value:

$$
W e_{d} \equiv \frac{\rho_{d} U^{2} D_{d}}{2 \sigma_{d}} \geq C_{b 1}
$$

where $\mathrm{C}_{\mathrm{b} 1}$ is the critical Weber number and a model coefficient and $\mathrm{U}$ is the relative velocity of the droplets with respect to the gas phase. All model coefficients and their values used in these simulations can be found in Table A1. The stable droplet diameter can be found using Eq.A2 when the droplet Weber number is equal to the critical Weber number:

$$
D_{d, \text { stable }}=\frac{2 C_{b 1} \sigma_{d}}{\rho_{d} U^{2}}
$$

The corresponding break-up timescale can be calculated as follows:

$$
\tau_{b}=\frac{C_{b 2} \rho_{d}^{0.5} D_{d}^{1.5}}{4 \sigma_{d}^{0.5}}
$$

where $\mathrm{C}_{\mathrm{b} 2}$ is another model coefficient. Using this break-up timescale and the stable droplet diameter from Eq.A3, Eq.A1 can be solved to calculate the bag droplet break-up rate.

\section{Strip Break-Up}

For strip break-up to occur a different criterion is used:

$$
\frac{W e_{d}}{\sqrt{R e}_{d}} \geq C_{s 1}
$$

When this criterion is met then stripping break-up can occur. Again, the stable droplet diameter can be calculated when the left and right hand side of Eq.A5 are equal to each other:

Page 12 of 16 


$$
D_{d, \text { stable }}=\frac{4 \sigma_{d}^{2} C_{s 1}^{2}}{\rho_{d} U^{2} \mu_{d}}
$$

where $\mathrm{C}_{\mathrm{s} 1}$ is a model coefficient. The stripping break-up timescale can be calculated as follows:

$$
\tau_{s}=\frac{C_{s 2}}{2}\left(\frac{\rho_{d}}{\rho_{g}}\right)^{0.5} \frac{D_{d}}{U}
$$

with $\mathrm{C}_{\mathrm{s} 2}$ another model coefficient. As before, using this break-up timescale and the stable droplet diameter from Eq.A6, Eq.A1 can be solved to calculate the stripping droplet break-up rate.

Table A1 - Reitz-Diwakar model coefficients and their values used in simulations

\begin{tabular}{|l|l|}
\hline $\mathrm{C}_{\mathrm{b} 1}$ & 6 \\
\hline $\mathrm{C}_{\mathrm{b} 2}$ & $\pi$ \\
\hline $\mathrm{C}_{\mathrm{s} 1}$ & 0.5 \\
\hline $\mathrm{C}_{\mathrm{s} 2}$ & 20 \\
\hline
\end{tabular}

\section{KH-RT Break-Up Model}

\section{Kelvin-Helmholtz Break-Up}

The KH model predicts the growth rate and wavelength of surface waves on each droplet at the flow conditions [39]. With this knowledge the child droplet radius and break-up timescale can be calculated. The growth rate and wavelength correspond to the maximum computed surface wave growth rate, as this will cause droplet break-up in the shortest possible time and is hence the critical break-up mechanism. The wavelength $\left(\Lambda_{\mathrm{KH}}\right)$ can be calculated as follows:

$$
\Lambda_{K H}=9.02 \frac{r_{p}\left(1+0.45 Z_{d}^{0.5}\right)\left(1+0.4 T^{0.7}\right)}{\left(1+0.87 W e_{g}^{1.67}\right)^{0.6}}
$$

with $\mathrm{Z}_{\mathrm{d}}$ being the droplet Ohnesorge number and $\mathrm{T}$ the Taylor number, both calculated as:

$$
\begin{gathered}
Z_{d}=\frac{\sqrt{W e_{d}}}{R e_{d}} \\
T=Z_{d} \sqrt{W e_{g}}
\end{gathered}
$$

with the Weber numbers for droplets $\left(\mathrm{We}_{\mathrm{d}}\right)$ and gases $\left(\mathrm{We}\right.$ ) being calculated as in Eq.A2. To calculate the maximum surface wave growth rate $\left(\Omega_{\mathrm{KH}}\right)$ the following calculation is performed:

$$
\Omega_{K H}=\left(\frac{\sigma_{d}}{\rho_{d} r_{p}^{3}}\right)^{0.5} \frac{\left(0.34+0.38 W e_{g}^{1.5}\right)}{\left(1+Z_{d}\right)\left(1+1.4 T^{0.6}\right)}
$$

When the maximum surface wave growth rate and wavelength have been calculated, the child droplet radius can be found: Page 13 of 16 


$$
r_{c}=B_{0} \Lambda_{K H}
$$

with $\mathrm{B}_{0}$ being a model coefficient. All KH-RT model coefficients and their values used in these simulations can be found in Table A2. Finally, the break-up timescale can be calculated:

$$
\tau_{K H}=\frac{3.726 B_{1} r_{p}}{\Lambda_{K H} \Omega_{K H}}
$$

with $\mathrm{B}_{1}$ as a model coefficient. The results from Eq.A13 and Eq.A14 can be used in Eq.A8 to calculate the parent droplet break-up rate.

\section{Rayleigh-Taylor Break-Up}

The RT model simulates the instabilities on the droplet surface due to the aerodynamic drag acting on the droplets. This drag is calculated in the form of an acceleration (aRT), which is then applied to the viscid form of the RT model [40]. The drag acceleration is calculated as follows:

$$
a_{R T}=\frac{3}{8} C_{d} \frac{\rho_{g} U^{2}}{\rho_{d} r_{p}}
$$

The value for the drag coefficient $\left(\mathrm{C}_{\mathrm{d}}\right)$ is dependent on the Reynolds number:

$$
C_{d}=\left\{\begin{array}{l}
R e \geq 1000, \quad C_{d}=0.424 \\
R e<1000, C_{d}=\frac{24}{\operatorname{Re}}\left(1+\frac{1}{6} R e^{0.6667}\right)
\end{array}\right.
$$

As in the KH model described above, the maximum surface wave growth rate $\left(\Omega_{\mathrm{RT}}\right)$ is the critical break-up mechanism. Within the viscid RT model the surface wave growth rate is found from:

$$
\omega_{R T}=-k_{R T}^{2}\left(\frac{\mu_{d}+\mu_{g}}{\rho_{d}+\rho_{g}}\right)+\sqrt{k_{R T}\left(\frac{\rho_{d}-\rho_{g}}{\rho_{d}+\rho_{g}}\right) a-\frac{k_{R T}^{3} \sigma_{d}}{\rho_{d}+\rho_{g}}+k_{R T}^{4}\left(\frac{\mu_{d}+\mu_{g}}{\rho_{d}+\rho_{g}}\right)^{2}}
$$

where $\mathrm{k}_{\mathrm{RT}}$ is the wavenumber. The wavenumber that corresponds to the maximum surface wave growth rate is $\mathrm{K}_{\mathrm{RT}}$, and is found using a numerical bisection method from Eq.A17 within Code 2. This value of $\mathrm{K}_{\mathrm{RT}}$ is then substituted into Eq.A17, replacing kRT, to find the maximum surface wave growth rate $\left(\Omega_{\mathrm{RT}}\right)$. The wavelength that corresponds to this growth rate is calculated as:

$$
\Lambda_{R T}=\frac{2 \pi}{K_{R T}}
$$

Finally, the child droplet radius and break-up time can be calculated:

$$
\begin{gathered}
r_{c}=B_{2} \Lambda_{R T} \\
\tau_{R T}=\frac{B_{3}}{\Omega_{R T}}
\end{gathered}
$$

Page 14 of 16 
with $\mathrm{B}_{2}$ and $\mathrm{B}_{3}$ as the RT model coefficients. As with the KH model before, the results from Eq.A19 and Eq.A20 are used with Eq.A8 to calculate the parent droplet break-up rate.

Table A2 - KH-RT model coefficients and their values used in simulations

\begin{tabular}{|l|l|}
\hline $\mathrm{B}_{0}$ & 0.6 \\
\hline $\mathrm{B}_{1}$ & 7 \\
\hline $\mathrm{B}_{2}$ & 0.1 \\
\hline $\mathrm{B}_{3}$ & 1 \\
\hline
\end{tabular}

Page 15 of 16 


\section{Rebuttals}

\section{Review 1}

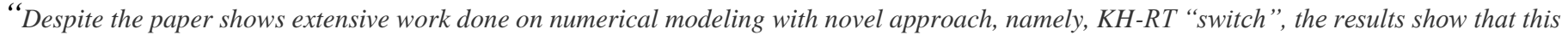
model does not provide good prediction of most spray and combustion parameters, except for liquid length. It is suggested that the model to be

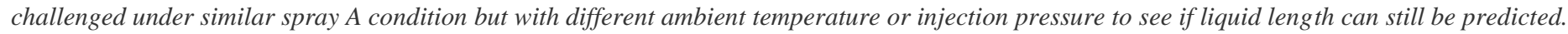

Again, the paper provides good fundamental investigation of CFD tool. But the direction should be more focused under non-reacting spray.

- How is comparison between liquid and vapor penetration profile with ECN experimental data?

- How about spray cone angle?

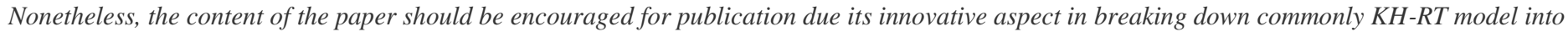
individual sub models to investigate their impacts on both spray and combustion parameters such as liquid length, and LOL."

Thank you for your comments on the paper. The adjustments suggested can be found as follows:

\section{Comparison to ECN Experimental Data:}

The following paragraph was entered in Page 4, along with Table 4, showing the comparison of the non-reacting spray to the global liquid and vapour lengths:

"These cases were considered in the previous study [15], with the liquid length means and vapour lengths shown in Table 4. As can be seen, the

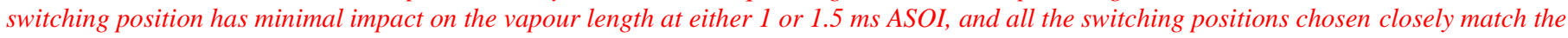
baseline Reitz-Diwakar case's vapour length."

This now follows on straight to comments about the spray cone angles, with Table 5 showing the comparison at multiple times ASOI.

\section{Review 2}

Reviewer 2 provided no comments on the paper, however I'd like to thank you for the scores given on the paper. 